\title{
Handbook of behavior genetics: from Greeks to Geeks
}

\section{Arpana Agrawal*}

Department of Psychiatry, Washington University School of Medicine, Saint Louis, MO, USA

*Correspondence: arpana@wustl.edu

\author{
A book review on \\ Handbook of Behavior Genetics \\ by Yong-Kyu Kim, New York, NY: Springer Science+Business Media, LLC, 2009, 1st Edn
}

The handbook of behavior genetics (HBG) includes a diverse and fairly comprehensive compilation of chapters on topics ranging from human behavioral laterality to animal models of aggression. An outstanding introductory chapter on the history of behavior genetics guides the reader from the earliest references to inheritance of behavior in Homer's Odyssey to the establishment of the Behavior Genetics Association, addressing both accomplishments and controversy. Penned, inimitably, by behavior genetics' own poet laureate, Professor John Loehlin, the chapter is as incisive as its influential author, who is well recognized for paradigm shifts in behavioral genetics, quantitative psychology, and applied statistics and computer programming. Charting progress made in behavior genetic studies of normative behavior (e.g., personality) as well as psychopathology (e.g., autism), the book's didactic goals are also well served by a series of three superlative chapters on quantitative methodology that are amongst the most readily accessible writings on the topic. These features alone, make HBG an excellent companion text for undergraduate and graduate courses on behavior genetics, recommended reading for scientists seeking an introduction to the research area and a fine reference for the seasoned behavior genetics investigator.

Handbook of behavior genetics is broadly divided into four sections (Quantitative Methods and Models, Genetics of Cognition, Genetics of Personality, and Genetics of Psychopathology), however, the reader should not be misled by these pithy titles. Each section covers a broad range of topics. For example, the section on the Genetics of Psychopathology includes chapters on attention deficit hyperactivity disorder (ADHD), autism, internalizing disorders (e.g., depression, anxiety) during childhood, smoking, substance use disorders, conduct disorder, and antisocial behavior, Schizophrenia, and affective psychoses as well as a chapter on working memory. This scope is unlike other texts on the topic, which have tended to over-emphasize the rarer and potentially more serious Axis I psychiatric illnesses (Schizophrenia and Autism), perhaps due to the considerable molecular genetic advances made in the etiology of those disorders.

As one of a few texts on the area of behavior genetics, HBG does a fine job of guiding readers through research on human cognition, extending from an excellent general introduction to mental ability with references to classical genetically informative methodology to highly citable chapters on human brain volumes, neurogenetics, and specific developmental disorders. Often extremely popular with the student reader (and the impetus for several student assignments), emerging topics such as exercise, sexuality, and voting preferences are also elegantly reviewed. HBG uses a combination of detailed tables (some of which are likely to be definitive), figures, and graphs to relay important aspects of the chapter. The book closes with a chapter on Future Directions which artfully captures salient themes (such as evolution, epigenetics, obesity) that a future edition may address. These are, indeed, worthy of addition.

While it was only partly intended to be so, HBG is obviously a highly attractive option as a teaching tool. However, if the book is to be more widely and wholly adopted as a standalone course textbook, there are a few areas that might benefit from further review. First, individual chapters lack an overall consistent pattern of presentation. For a student who is relatively new to the area, these fluctuations in density of research coverage, ranging from chapters with a focus as constricted as a single gene family to as broad as an entire family of related syndromes, can often be distracting. This caveat, if it is to be called that, in no way detracts from the quality of the chapters - it is simply the problem of comparing
Hemingway and Dickens, each a master in his own accord. Future editions may wish to consider providing a content outline to these expert contributors to facilitate greater uniformity in presentation.

Second, while comprehensively addressing the area of psychopathology, a chapter on adult mood disorders, is lacking. There is, however, an excellent chapter on depression and anxiety during childhood and adolescence. Likewise, a chapter dedicated to aging (intended for a future edition) may supplant the multiple mentions of its behavioral manifestations across the various chapters. Finally, while a challenge to compile, a glossary of terms would be exceedingly useful, especially to the student reader.

A well-thumbed copy of HBG earns a spot on the bookshelf of this course instructor and researcher with high marks for content, layout, and a handy softcover version with $11^{\prime \prime} \times 8^{\prime \prime}$ pages that are perfect for bleary-eyed midnight lecture preparation. Competitively priced, the publishers offer select access to the eBook version and individual chapters may be purchased in pdf format. An online desk copy is also available for review; however, a non-pdf version for portable reading devices (e.g., Kindle, Nook, iPad) appears to be currently unavailable.

Overall, HBG is good reading for the novice and the aficionado alike. Editor Kim dedicates this first edition to his teachers we should all be so fortunate to receive such a gift in return for mentorship.

Received: 23 January 2012; accepted: 23 January 2012; published online: 07 February 2012.

Citation: Agrawal A (2012) Handbook of behavior genetics: from Greeks to Geeks. Front. Gene. 3:16. doi: 10.3389/ fgene. 2012.00016

This article was submitted to Frontiers in Behavioral and Psychiatric Genetics, a specialty of Frontiers in Genetics. Copyright () 2012 Agrawal. This is an open-access article distributed under the terms of the Creative Commons Attribution Non Commercial License, which permits noncommercial use, distribution, and reproduction in other forums, provided the original authors and source are credited. 